the assistance, miscalled interference, rendered them by the sealth officers.

3. I have inquired of the two registrars as to the number of deaths certified by chemists and other unqualified persons. One with an experience of over eighteen years tells me that in all that time he has had none in adults. The other in five years has had one adult death certified by a herbalist. The only exceptions given by both are those of babies, all under one week old and certified by midwives. These are very infrequent. In every case where the death is not certified by a qualified practitioner the registrars invariably communicate with the coroner, who uses his discretion as regards an inquest. I think these facts refute this objection, at least as applied to Reading.

But why should Dr. Jacob require a mathematical demonstration of lessened death-rate through compulsory notification? Attached to zymotic disesse is a certain percentage of deaths. In compulsory notification we have a machinery by which the spread of these diseases may be reduced, and therefore, potentially, a certain number of deaths prevented. If preventive medicine be equally with curative a function of the practitioner, I do not think I require stronger ground for my advocacy. Some two or three years ago the late Dr. Shea observed that notifications of diphtberia were coming in from one particular district, and on inquiry found that all the children first attacked attended the same Board school. Inspection showed that the sanitary condition of the school was defective, and the school was immediately closed until the defects were remedied and the outbreak was at an end. This is one out of many instances in which we have been indebted to compulsory notification.

The following extracts from the last report, dated January 1887, by our late medical officer of health, still further illussrate the advantages of this institution:- "No outbreak of opidemic disease has arisen during the year requiring the compulsory closure of any elementary school, but the asual precautions of recording the names of the schools attended is continued, and children from infected houses are prevented from attending Sunday and day schools, or other gatherings. The compulsory notification clause is much needed in the suburbs, where cases often srise that are not notified." "In several instances, upon my advice, the work of needlewomen, laundresses, and other persons was stopped where scarlet fever existed in their houses, compensation to a moderate extent being paid them for the time; and the power to do this was very useful, and to a great extent prevented hardship, for the relieving rfficer could afford no aid beyond offering 'the house' to the entire family, which would have broken up their home." "Small-pox was very prevalent in the county of Berks, and in adjacent districts last year several troublesome outbreaks occurred. The infection was brought into the borough on four occasions; but the cases being at once removed, and the ordinary precautions adopted on the premises from whence they came, there was no extension of the disease. This was the more fortunate, as the cases arose in very small houses and in two small beer-houses of a very similar class to a common lodging-house." Again, having in view the still further perfecting of his preventive measures he writes: "Scarlet fever was rather prevalent. A mild type existed, and though 236 cases were reported only eight proved fatal. A few were isolated in the cottage. Notification of cases of scarlet fever without the means for isolating them is very much reduced in walue. Children from infected houses can be prevented from attending school, certain trades can be controlled, and where scarlet fever prevails the taking in of needlework and washing can be prevented, but the chief means for arresting the disease is wanting if the first cases cannot be removed to a hospital." Dr. Shea boped that in time he might be able to establish a small hospital for infectious isolation. Lastly: "Notification of disease has proved very useful in several instances during the past year. Since notification has been in force it has worked very smoothly, and without any friction or difficulty. This, II think, greatly arises from the fact that we have in Reading a body of gentlemen practising medicine who have always whown the most perfect willingness to assist in every way in their power in the prevention of the spread of infectious disease."

Such was the opinion of a most unprejudiced and very experienced sanitarian on the value of compulsory notification. In support of $\mathrm{my}$ plea for its national adoption I cannot do better than allude to an address on the National Value of Public Health, delivered by Sir James Paget, and published in the journals in June, 1884. In this, he says : "I take it for granted that a large portion of all national welfare is dependent on the work which the population can constantly be doing; or, if I may so express it, that the greater part of the national wealth is the income from the work which is the outcome from the national health." Then after dealing with statistics, he continues: "Thus we may believe that our whole population between fifteen and sixty-five years old do, in each year, $20,000,000$ weeks' work less than they might do if it were not for sickness." After calculating this loss to the country in millions of pounds, he remarks: "The losses of work due to sickness.among children must be very large. Consider the time which might be spent in good productive work if it were not spent in taking care of them while they are ill." He then refers to losses due to the deaths of those who die young, which he estimates at much more than $£ 2,000,000$ sterling per annum. After apologising for making money appear as a motive for doing things for which sufficient motives might be found in charity and sympathy, this eloquent and distinguished advocate, in answer to the question "What more is wanted?" replies: "A larger and more practical recognition of the value and happiness of good national health; a wider study and practice of all the methods of promoting it; or, at least, a more ready and liberal help to those who are striving to promote it."

On the grounds of philanthropy and of political economy, I venture to express the hope that the opponents of compulsory notification may at length recognise that in it we possess a method capable of beneficent results to the nation at large, and in no way inimical to the interests of the medical profession.

I am, Sirs, yours faithfully,
Reading, Oct. 17th, 1887.

\section{THE PURGATIVE TREATMENT OF PERITONITIS.} To the Editors of THE LANCET.

Srns,--I am quite disposed to attribute the success in Mr. Frank Sturges' case to the purgative pills, though I wish to point out that my advocacy of this treatment was confined to the peritonitis following surgical operations-a very different thing from the peritonitis of childbed. In Mr. Sturges' case the purgatives were given before vomiting was established, and they probably therefore got a chance of being effective. To be of any use the purgative treatment must be employed early, before distension has paralysed the intestines, and before incessant vomiting has made every effort to do anything by the stomach of no avail. In fact, I look upon the purgative method rather as a preventive of, or as a method of aborting, peritonitis, than as a way of curing it. This will be quite evident to anyone reading my paper on the subject. Yet very far advanced peritonitis may be cured by this method if the vomiting can be stopped, and this is best done by putting nothing, absolutely nothing, in the stomach for twenty-four or even forty-eight hours, and giving a fairly large dose of morphia by hypodermic injection. But puerperal peritonitis has as its base in very many cases a specific poison, against which purgatives and everything else are powerless. Even opening the abdomen and cleaning it out fails to obtain the large success in puerperal cases which it certainly has, in my hands at least, in suppurative peritonitis which is non-puerperal. I am, Sirs, yours obediently,

Birmingham, Oct. 15th, 1887. Lawson TatT.

\section{PROTECTION BY COMPLETE VACCINATION.} To the Editors of THE LANCET.

SIrs,-It may interest the public to know how completely two children were protected from small-pox by having been fully vaccinated.

I was called to a club patient suffering from small-pox, having taken the disease from his wife. Seeing that the wife, then just convalescent, was nursing a baby five months old who was perfectly well, and who had had but a pimple on its nose, which never proceeded to suppuration, I inquired if the child had been vaccinated, and examined the arms, which bore five large cicatrices each. Observing that I took notes of the case, the mother told me that $\mathrm{a}$ friend of her's, who took the disease after visiting her (living in the next house), also had a balby whith' was 